\title{
The pulsing structure of science: Ortega y Gasset, Saint Matthew, fractality and transfractality
}

\author{
RAFAEL BAILÓN-MORENO, ${ }^{\text {a }}$ ENCARNACIÓN JURADO-ALAMEDA, ${ }^{\mathrm{a}}$

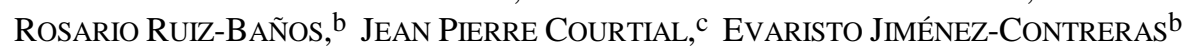 \\ a Departamento de Ingeniería Química, Facultad de Ciencias, Universidad de Granada, Granada (Spain) \\ b Departamento de Biblioteconomía y Documentación, Facultad de Biblioteconomía y Documentación, \\ Universidad de Granada, Granada (Spain) \\ ${ }^{\mathrm{c}}$ Laboratoire de Psychologie - Education - Cognition Développement (LabECD), Université de Nantes, \\ Nantes (France)
}

\begin{abstract}
By a new fractal/transfractal geometry of the Unified Scientometric Model, it is possible to demonstrate that science presents an oscillating or pulsing dynamic. It goes alternatively through two types of phases. Some phases are fractal, with crystalline networks, where the Matthew effect clearly manifests itself with regard to the most notable actors and those that provide the best contributions. The other phases are transfractal, with deformed, amorphous networks, in which the actors, considered mediocre, present greater capacity to restructure the network than the more renowned actors. The result after any transfractal deformation is a new crystalline fractal network. Behind this vision lies the Kuhn paradigms. As examples, the scientific fields of surfactants and autism have been analysed.
\end{abstract}

\section{Introduction}

The scientific activity of authors has historically been defined by two opposing, even incompatible, positions.

The metaphor of dwarfs standing on the shoulders of giants (Pigmaei gigantum humeris impositi plusquam ipsi gigantes vident) is well-known and is first recorded in the 12th century, attributed to Bernard of Chartres. The attribution to Bernard is due to John of Salisbury, who writes in 1159 in his Metalogicon:

Received January 9, 2006

Address for correspondence:

RAFAEL BAILÓN-MORENO

Departamento de Ingeniería Química, Facultad de Ciencias

Campus de Fuentenueva, Universidad de Granada, 18701-Granada, Spain

E-mail: bailonm@ugr.es

0138-9130/US \$20.00

Copyright () 2007 Akadémiai Kiadó, Budapest

All rights reserved 
"Bernard of Chartres used to say that we are like dwarfs on the shoulders of giants, so that we can see more than they, and things at a greater distance, not by virtue of any sharpness on sight on our part, or any physical distinction, but because we are carried high and raised up by their giant size."

The 13th century stained glass of the south transept of the Chartres Cathedral may also be influenced by the metaphor. The tall windows under the Rose Window show the four major prophets of the Hebrew Bible (Isaiah, Jeremiah, Ezekiel, and Daniel) as gigantic figures, and the four New Testament evangelists (Matthew, Mark, Luke, and John) as sitting on their shoulders. The evangelists, though smaller, "see more" than the huge prophets (they saw the Messiah about whom the prophets spoke).

Also several later authors have mentioned the metaphor. For example, we know that Newton writes in a letter to Robert Hooke, dated 5 February 1676:

"If I have seen a little further it is by standing on the shoulders of Giants."

The first empirical evidence discovered by Lotka, ${ }^{1}$ and expanded by Price, ${ }^{2}$ revealed that scientific productivity has a strongly biased distribution, in which a few authors are responsible for the most significant part of science. This fact is complemented with the so-called Saint Matthew effect, inspired by "The Parable of the Talents" of the Evangelist (Matthew, chapter 25, verses 14-30) and defined by Merton. ${ }^{3}$ According to this effect, eminent authors are assigned a comparatively greater part of the scientific credit at the expense of the lesser known and less prestigious ones, even in cases of joint collaboration. In fact, according to the brothers Cole, ${ }^{4}$ important scientists are in fact the motor of science, contributing important information, resolving truly relevant scientific problems, and consequently concentrate the greatest quantity of resources and receive the greatest recognition as well as most of the citations (which would be one part of this recognition). Meanwhile, the rest of the scientific community, called "mediocre", provide little of significance and without them scientific progress would not diminish and would even register a general gain in effectiveness, since fewer but more brilliant scientists would be more effective in advancing science. Scientific progress would depend essentially at each point on a few eminent scientists (from a few prestigious institutions, etc.), while the rest of the scientific community would support this minority without contributing anything meaningful, or very little. In the vision of Cole, the Saint Matthew effect, or simply the Matthew effect, would be nothing more than the natural recognition, by the research community, of this dynamic of science.

In opposition to this position, José Ortega y Gasset ${ }^{5}$ in 1929 formulated a hypothesis according to which all scientists, even the mediocre ones, fulfilled their missions by helping the general scientific progress thanks fundamentally to the effectiveness of the system itself to operate what modern science had developed. This state of affairs could be summarized in the famous aphorism of Ortega: "I am myself and my circumstances." 
In this case the scientific circumstances, the tremendous effectiveness of modern science, in words of the Ortega, would determine the functional success of the scientists regardless of their intellectual worth.

In contrast to Merton and the Cole brothers, Ortega y Gasset was not a sociologist nor a philosopher, and his proposal was not developed but rather was to be refuted years later in the article of the Coles, who, paradoxically, were responsible for the spread of the so-called Ortega Hypothesis among the circles of specialists in the sociology of science and in library science. The hypothesis became known precisely to demonstrate its inaccuracy with respect to the evidence in favour of the biased and concentrated distribution of scientific merit among a select few.

These two stances have had defenders, although it should be mentioned that most of the empirical works tend to confirm the leading role of the scientific élite over the value of mediocre scientists. This is because, as with productivity, the citations tend to be concentrated systematically in a comparatively small number of scientists, as demonstrated by Garfield ${ }^{6}$ in works on the way in which citations of the journals recognized in the ISI concentrate on a small fraction of journals.

Historically, the Ortega Hypothesis suffered the problem of the choice of the word "mediocre" to indicate authors that had not reached a noted position in their scientific field. These authors, less productive and not leading the dominant scientific paradigms, would however be the breeding ground for the theories that would call the paradigms into question. The problem is therefore not limited to weighing brilliant scientists against dull ones, but rather can be viewed from the perspective of established vs. revolutionary scientists.

An analysis of these two perspectives, so opposed to one another concerning the functioning of science, should take into account that, from the standpoint of sociology of science, there is another vision, equally fundamental, formulated by Kuhn. ${ }^{7}$ According to this view, science operates basically in two situations: the normal or paradigmatic, in which the scientific community shares and manages a set of principles; and the revolutionary or non-paradigmatic one, which arises when a set of these principles is questioned. This situation lasts until a new paradigm with its principles becomes dominant. With greater or lesser frequency, science (the different scientific specialties) go through these revolutionary phases.

The theory of the paradigms, or the disciplinary matrix, as it was later called by Kuhn himself, has been refined later by different authors. It is almost a constant situation of confrontation between the different theories and their corresponding followers which vie for a dominant position. An answer given by Kuhn indicates that the followers of a displaced paradigm do not convert to the new one, but rather fade with the old, being replaced by new scientists, who are younger and who follow the new dominant disciplinary matrix. 
Although originally presented as a clash of ideas and of their proponents, it is easy to see that the ideas of Kuhn are at the base of the actor-network theory, with the added element that this theory broadens the sphere of this confrontation to all the ambits of scientific activity (authors, ideas, resources, etc.).

According to the Actor-Network Theory of Callon and Courtial, Science and Technology (Technoscience) are comprised of networks of actors. ${ }^{8}$ That implies:

a) Those entities that create and modify Technoscience are called actors.

b) Actors can be defined by words taken not as linguistic or meaning units but only as verbal or scriptural productions in associated to action, in other words like a kind of elemental action (verbal definition).

c) Actors can be defined according to their relative position in the network (strategic definition).

d) Actors can be human or non-human (researchers, laboratories, countries, scientific journals, research topics, documents, measuring devices, financing, etc.). No distinction is made between them, as all are equally necessary to construct Technoscience.

e) Technoscience is comprised of a network of interconnected actors.

f) A network is not homogeneous, but rather have areas of greater interconnection, called interest centres. The interest centres are actors.

The dynamics of the technoscientific networks are governed by Latour's Translation Theory. ${ }^{9-20}$ That implies, among other matters, the following:

a) The verbal definition of the actors evolves over time by the imposition of positive and negative modalities (linguistic meaning of the translation).

b) The position of the actors within the network and their strategic situation also change with time (geometric meaning of the translation).

c) Translations involves the equilibrium between natural and social interactions and stabilization of the actors. Translations depend on the particular or collective interests of the actors, on their strategic advantage, and on their intrinsic strength.

Also, the translation implies the existence of a space according to Fractal Theory of Mandelbrot, with temporal and geometric components of the Hausdorff-Besicovitch type and whose dimensions are fractionary. ${ }^{21-29}$ According to Bailón-Moreno, as opposed to the Mandelbrot model, the conditions of fractality are not necessarily imposed, but that are a particular case of a model more general than is called fractal/transfractal. ${ }^{30-32}$

Returning to the starting point on the opposition between the proposals of Cole and the Ortega Hypothesis, and without examining the arguments in favour of one or another, we find that both theories seek to characterize, without conclusive statements until now, the general activity of scientists. 
The data provided in the present work point to a solution that reconciles the two positions. That is, scientific activity can pass through phases in which the élite play the more decisive role (normal science, regardless of whether we examine a great specialty or a small scientific domain) and others more open to the contributions of non-dominant scientific groups that try to gain positions and impose their own paradigm. In fact, it is conceivable that, if the scientifically dominant groups and the theories or paradigms that they defend always occupied this position, there would be no de facto scientific renewal. The moment at which, for reasons of internal development of a discipline, the dominant disciplinary matrix is questioned, a readjustment of the network occurs as new actors move to the centre. This process can be modelled in accordance with the proposal in the present work.

For this, two examples related to the dynamics of science will be presented. The first example is the case of the scientific field of autism, where the temporal evolution of the structure of the network is analysed. The second example is the case of the scientific field of surfactants, using a quantitative analysis of translation according to the unified Scientometric Model. Both perspectives are inscribed within the actor-network theory and recognize fractal/transfractal geometry as the necessary instrument for interpretation.

\section{Analysis of the structures of the networks. The case of the network of autism}

The subject of this section is the development of scientific knowledge concerning autism. ${ }^{11,13}$ A new scientific development is usually represented by a linear structure. For instance, the discovery of the role played by endorphins in autism is shown by the effect of an excess of endorphins on the tendency towards self-mutilation, and that of the therapeutic role played by a drug which counters the effects of the endorphin, such as naltrexone. However, this does not take into consideration the fact that, insofar as the logic of discovery is concerned, the role played by endorphins was revealed at diverse levels, from blood analysis to drug testing. Thus, problems of autism and endorphins have been associated at very precise levels of blood analysis, as well as at more general levels of therapeutic effects. Networks associated with autism, on the one hand, and those with endorphins on the other, are joined in variable clusters, according to the frequency of variable occurrences, rather low for blood analyses, moderately high for therapeutic trials, and high for general considerations concerning autism. Figures 1 and 2 are simplified diagrams derived from computed data, following the PSYCINFO database: 
Autism network

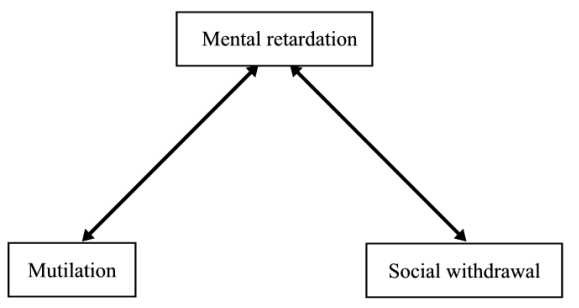

Figure 1. Association network before the endorphin theory

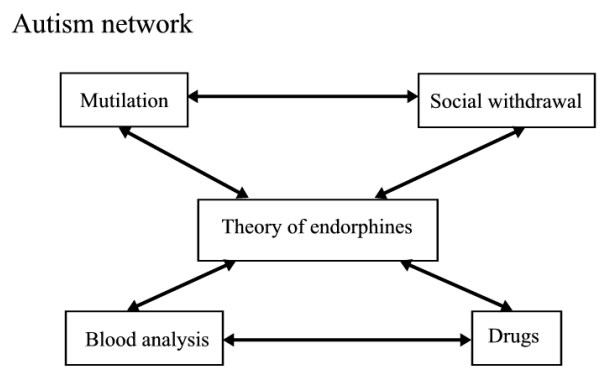

Biology network

Figure 2. Network of associations after the endorphin theory

In fact, the researcher sees a connection between the two networks: the network associated with autism and the one associated with endorphins. The two are associated, because as a biologist the researcher has been in contact with animals displaying excessive levels of endorphins. This association is made because the researcher has training in two different spheres, biological as well as psychological. This consistently poses the question of the "self" and "the other": How am I not the other, and how, according to what mechanisms, might I be the other? (in this case an autistic individual with self-mutilation tendencies). Here the fractal model characterizes both the object being studied and the observer. It should be remarked here that in the absence of a scientific theory of self-mutilation, the latter may be seen as a kind of choice made by the autistic child, a strange choice, often summed up as a case of "mental retardation" without further analysis. With this hypothesis, the researcher develops the link between two different spheres, biological and psychological, at different levels of analysis. In order to do this the researcher explores the associative network composed of the 
representation established of the body as an object. In doing so, the result is what the sociology of translation calls an actor network, in which the interactions among researchers, and those between the researchers and nature, consist of introducing sociocognitive equivalences. ${ }^{14}$ It is as much a question of the associative network describing the action mechanism of endorphins, as that of the associative network describing the mechanism of self-mutilation, observed for example at the level of the biting or of the pulling out of hair self-inflicted by the autistic child. When the discovery is seen as true within the researcher's area of expertise, when it can be stated causally in a linear manner, associative pathways exist in the researcher's mind which connect all these elements as co-occurrences, as well as causes.

Therefore, a new idea has an effect at different levels of the actor networks it challenges. Again using the example of the mind theory concerning autism, we find that the autistic child does not imagine what the other person is thinking and has no inkling of the other person's intentions. What the other person thinks is usually communicated by body language. In other words, the other person is an object with overall characteristics (in this case what is expressed in that person's relationship with us) that may be found at different bodily levels, from discreet movements, such as those of the eyes - for example, glancing at an object, which may imply thinking of that object - to the usual level of the thoughts expressed, opinions on people, in an example referred to as "social cognition", by way of intermediate levels, such as the facial expression of emotions. These mechanisms, observed at different levels, converge towards the idea of "the mind theory" (which is thus the theory of the other person's mind) (see Figure 3).

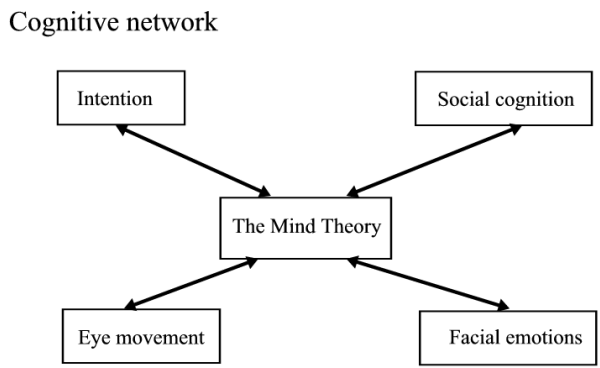

Physical network

Figure 3. Network of associations concerning the mind theory

These observations concerning eye movements form a cluster of words designating associated events, establishing a research object (especially via new devices which enable the precise measurement of eye movements). This is also the case for observations which analyse people's facial emotions and for observations concerning 
social cognition. The mind theory is an associative junction situated at the level of eye movements, facial emotions, and social cognition, forming an identical geometric pattern, though on various scales. Connexionism tells us that a shape such as the shape of the written letter "s", whoever the writer may be, its size, etc., corresponds to a very exact node, activated at the core of a formal neuronal network. However, this pattern, when knowledge is being acquired, cannot be defined precisely, as it will be later, when the knowledge is fully developed. It assumes its generally accepted name (the "game of pretending", for example, expresses the same shape or idea, more or less, in an earlier period of time but under different names, before being linked under the general label of "the mind theory"), only when the discovery has been completed.

When the discovery has been completed, it endows the network of associated words with a stable structure, an almost regular arborescence (tree structure), with the name of the discovery referred to most frequently at the root of the tree. The fractal dimension is weak, approaching, in a way, a rigid crystalline structure. This has been very clearly demonstrated recently, using mathematical models derived from fractal theory, by Bailon-Moreno, in the chemical field of surfactants.., $23-25$

In terms of the meaning of associations, a causal network surrounding an event is a network made up of fluxes, both centripetal and centrifugal, around the event. Heat induces swelling (a centrifugal link), and if there is swelling, there has been heat (a centripetal link). Seen from a biocognitive angle, scientific causal reasoning is thus a particular instance of thought.

Conversely, during explorative research, the new idea, often under different names, appears from the central areas of the fractal trees, corresponding to previous discoveries and knowledge. The fractal dimension is then very high, an expression, as Mandelbrot ${ }^{15}$ has shown for language, of the wealth of the vocabulary: the same idea is simultaneously expressed differently by different researchers. Scientific creativity is highest during these periods. Contributions by little-known researchers is referred to as the Ortega effect, in opposition to the Saint Matthew effect, when the most well-known researchers make the greatest contribution to the advancement of knowledge.

More generally, everything occurs as if the dynamics within a field of research were the consequence of discoveries of an earlier sort, mingled together, conferring a complex fractal structure upon the network of associated words. ${ }^{8}$ There is interference among hypotheses concerning endorphins and the mind theory. Thus, the dynamics of a field of research oscillates between a complex fractal (or transfractal) structure, with centres situated within a simple fractal structure in intermediary zones within the network of associated words.

Experts in a given field, shown networks of associated words, are frequently confused when they read the charts computed through co-word analysis. ${ }^{16}$ The latter do not propose the causal associations these experts are used to, as expressed in conventional science. The variations in the words used to deal with a discovery hamper 
the reading of associated-word networks. Moreover, the networks developed at different periods would have to be interlinked, preserving the words used in each period. This is why it is more convenient to prove the fractal nature of networks of knowledge from calculations of the sort used by Mandelbrot, concerning, in the case of usual language, the distribution of word frequencies. ${ }^{15}$

As has already been shown, through the actor-network concept, the sociology of science established the foundations of this model some years ago, via the theory of translation. ${ }^{14}$ The concept of the actor-network has been used in several fields of psychosociology. Translation, through which an equivalence between a problem of autism and a problem of endorphins, or of the mind theory is established, reaches its maximum at the roots of fractal trees. All the laws of scientometrics (the quantitative science of the development of knowledge) can be rediscovered from the fractal model of translation. ${ }^{8}$

Kuhnian sociology of the sciences employed the calculation of clusters of articles frequently referring to one another, calculations made by The Institute for Scientific Information (ISI), in Philadelphia. These articles were interpreted by the ISI in terms of "research fronts" linked to a precise paradigm - in general, a new hypothesis. The ISI even published a cartography of these research fronts for many years, under the title "An Atlas of the Sciences". ${ }^{17}$ These research fronts are composed of many articles referring to a small set of cited articles called core articles. Our approach poses as a hypothesis the emergence of a new form, linked in some cases to what might later be called a new paradigm, but this form is distributed to a number of sites in the network of word associations, and cannot be attributed simply to a small group of pioneers. This pattern cannot necessarily be interpreted in terms of a precise new hypothesis, as for example, in the language of experts when science and knowledge are completed. The pattern represents a new, barely visible dynamic, to the extent that the science it is linked to has not yet given rise to precise scientific statements. This explains why calculations and quantitative predictions made possible by fractal theory are preferable to reading charts of associated words indicating logical, linear links, as simple supporting paradigms, in the manner of the research fronts. It is from co-word analysis that numerous prospective analyses have been carried out to date, in the field of research management. ${ }^{14,18-22}$

\section{The Unified Scientometric Model and Ortega's Aphorism}

The Unified Scientometric Model is founded on seven principles: the actor-network, translation, spatial principle, quantitativity of translation, the composition of translations, central-peripheral, and the unified principle of accumulative 
advantage. ${ }^{30,23-25}$ This latter principle consists of an equation, which we call the Fundamental Equation of the Unified Scientometric Model:

$$
T=k s q,
$$

which recalls Ortega's aphorism (I am myself and my circumstances), cited above. This principle can be expressed in the following way: The capacity of Translation, $T$, of an actor depends on its intrinsic advantage, q, (of itself, of its "I") and of its strategic advantage, $s$ (of its relative position in the network, of its "circumstances"). Its final value of $T$ depends simultaneously on the relative values of these variables.

Considering the fourth principle of our model in which the translation is expressed mathematically as the derivate or the gradient of $q$ with respect to the spatial coordinate $x(T=\mathrm{d} q / \mathrm{d} x)$, and if we admit that $s=-1 /(x+m)^{\varphi}$ and that $q$ is also a function of $x$, we get the following differential equation:

$$
\frac{\mathrm{d} q(x)}{q(x)}=-k \frac{\mathrm{d} x}{(x+m)^{\varphi}},
$$

where $m$ is called the Mandelbrot distance and $\varphi$ the fractality index. When $\varphi=1$, the system is $100 \%$ fractal, but, with values less than $\varphi$, the fractal character diminishes, and after crossing the border of $\varphi=0$, the system is said to be transfractal. The value of $k$ is the inverse of the fractal dimension.

From Eq. 2., or different values of $m$ and $\varphi$, and for geometric coordinates of the rank type and temporal coordinates, all the known bibliometric distributions can be demonstrated: Laws of Zipf, Bradford and Lotka in all their variants, the law of exponential growth of science, and the law of ageing of Brookes. Also, we propose a unified law of Zipf of a stretched exponential type, as well as its unified equivalents for Bradford and Lotka.

Using the fifth principle of the Unified Scientometric Model, or Principle of Composition, it is possible for example to construct a Generalized Model of AgeingViability, the particular cases of which are Avarmescu's Law and Brookes' Law.

According to the Matthew Effect, or according to the Principle of Accumulative advantage, as proposed by Merton, ${ }^{3}$ Price ${ }^{33}$ or Bookstein, ${ }^{34}$ which depends on only one variable or advantage, the most benefited in absolute terms is invariably the actor who has the most, while the most harmed is the one having the least. If this were exclusively so, an actor with fewer advantages could never surpass those with more, and, on the contrary, no actor with good advantages could lose what had been accumulated. According to this, the bibliometric distributions would be temporally immovable, mute witnesses of the same elite that would go digging a trench between them and the rest of the mediocre community. On the other hand, the model that is proposed, represented by its Fundamental Equation, and like Ortega's aphorism (I am myself and my circumstances), depends on two variables in equilibrium. The case could arise that an actor might have good intrinsic qualities but is badly situated, or vice versa. In both 
situations, the actor will have poor capacity to translate or modify the surroundings. Conversely, when the intrinsic and strategic advantages are simultaneously high, the actor will be in a the most advantageous position possible. Evidently, the question is also to determine whether this supposed equilibrium evolves over time. Furthermore, our vision must be broader than that of Cole and Cole or that of Ortega y Gasset, as they refer only to researchers, human actors. In our system, we also include any other type of actor, such as journals, research centres and, above all, the most interesting in terms of reflecting the dynamic nature of science, thematic actors.

\section{Approach from the Unified Scientometric Model. The case of the surfactant network}

After a co-word analysis in the scientific field of surfactants divided into five twoyear periods from 1993 to $2002,{ }^{30,23-25}$ we will analyse with the proposed model the centrality and density values of the resulting themes. For this, combining Eq. 1 and Eq. 2, we calculate the translation $T$ of each theme as a function of its density and its centrality, using:

$$
T=-k \frac{F(x)}{(x+m)^{\varphi}} .
$$

For centrality, Eq. 3 takes on the following form:

$$
T_{c}=-k \frac{c}{\left(r_{c}+m\right)^{\varphi}},
$$

where $T_{c}$ - Translation according to centrality;

$c$ - Centrality;

$r_{c}-$ Centrality range (centrality of the strategic diagram).

And for density, Eq. 3 is:

$$
T_{d}=-k \frac{d}{\left(r_{d}+m\right)^{\varphi}},
$$

where $\quad T_{d}$-Translation in density;

$d$-Density;

$r_{d}$ - Density rank (density of the strategic diagram).

Due to the minus sign before the constant $k$, the values of $T$ are always negative. The more negative $T$ is, the greater the capacity of an actor to translate the surroundings and translate him/herself. This is only a question of the criterion of signs used, as for example in mechanics. A mobile object that moves with a velocity in absolute value, $|v|$, we can say, by a criterion of arbitrary signs, that when this velocity is towards the right it is $+v$ and when the velocity is towards the left it is $-v$, or vice versa. However, whatever the sign of this velocity, its size and kinetic energy, in absolute terms, is 
the same. A similar situation applies to translation. Nevertheless, so that the graphic representations are more intuitive, we have used the absolute value of $T$ (Figures 4 to 13).

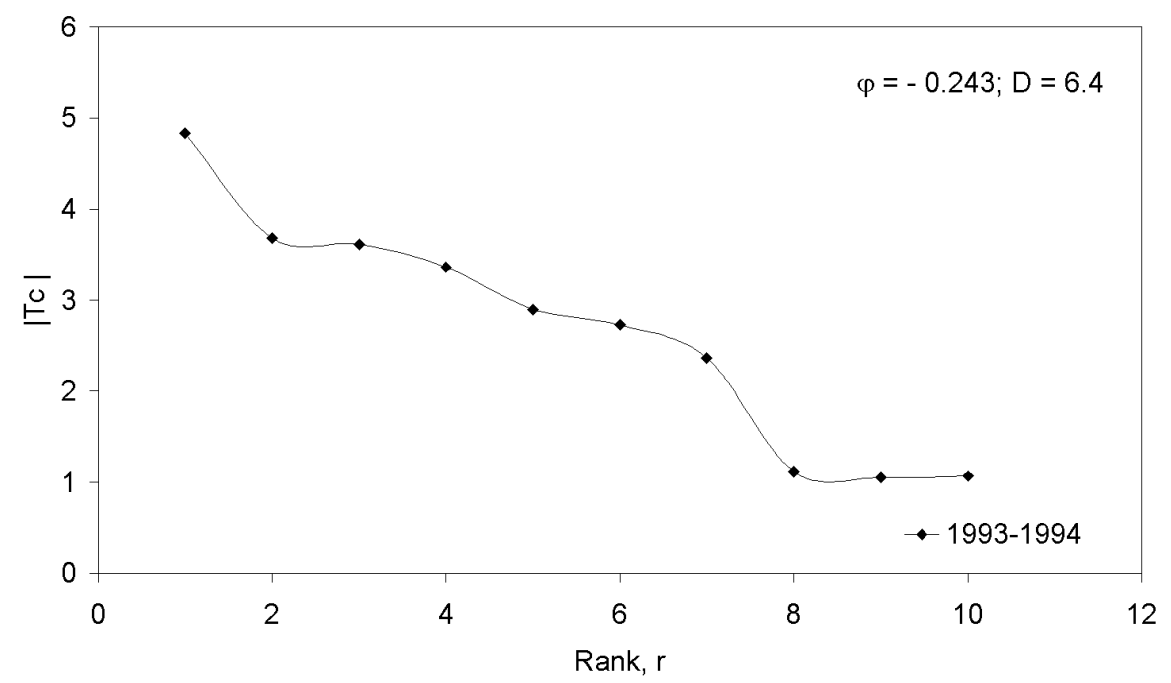

Figure 4. Profile of $T_{\mathrm{c}}$ for the period 1993-1994. The greatest translation capacity belongs to a theme of maximum centrality and declines gradually as centrality diminishes; $\varphi$ is slightly negative

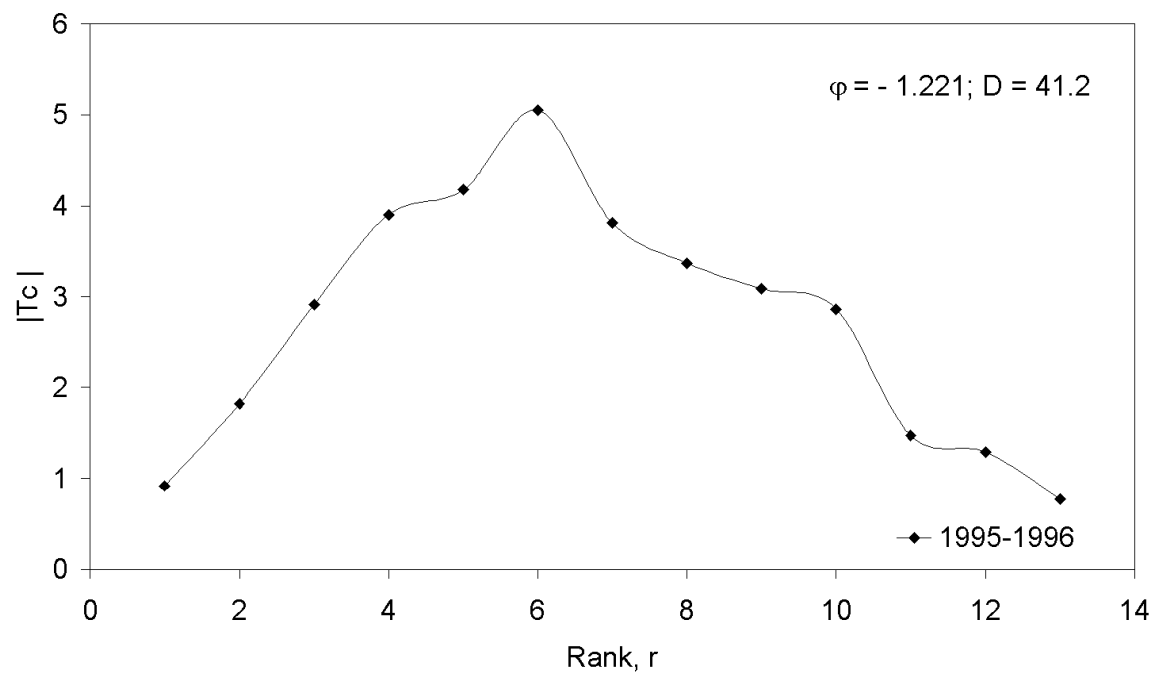

Figure 5. Profile of $T_{\mathrm{c}}$ for the period 1995-1996. The greatest translation capacity belongs to the theme in the sixth position, according to its centrality, situated in the middle of the distribution of ranks, in the mediocre zone; $\varphi$ is strongly negative 
R. BAILÓN-MORENO et al.: The pulsing structure of science

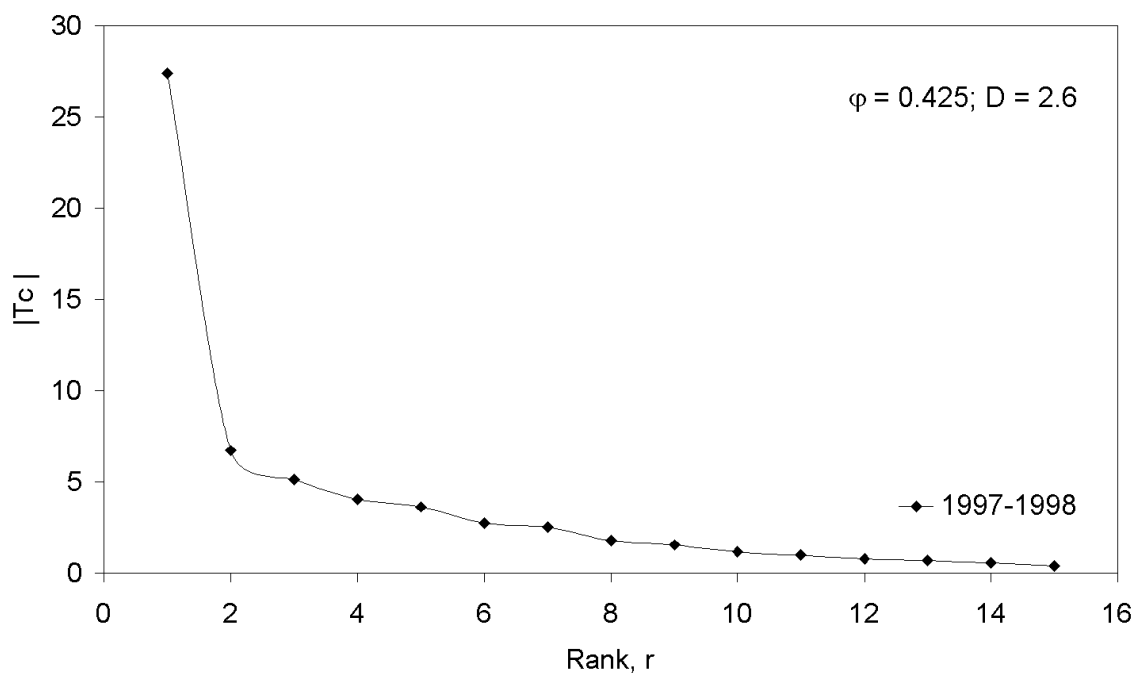

Figure 6. Profile $T_{\mathrm{c}}$ for the period 1997-1998. The greatest translation capacity belongs to the them of greatest centrality, but, $\varphi$ being positive, this theme stands out sharply from the rest; it represents an elite

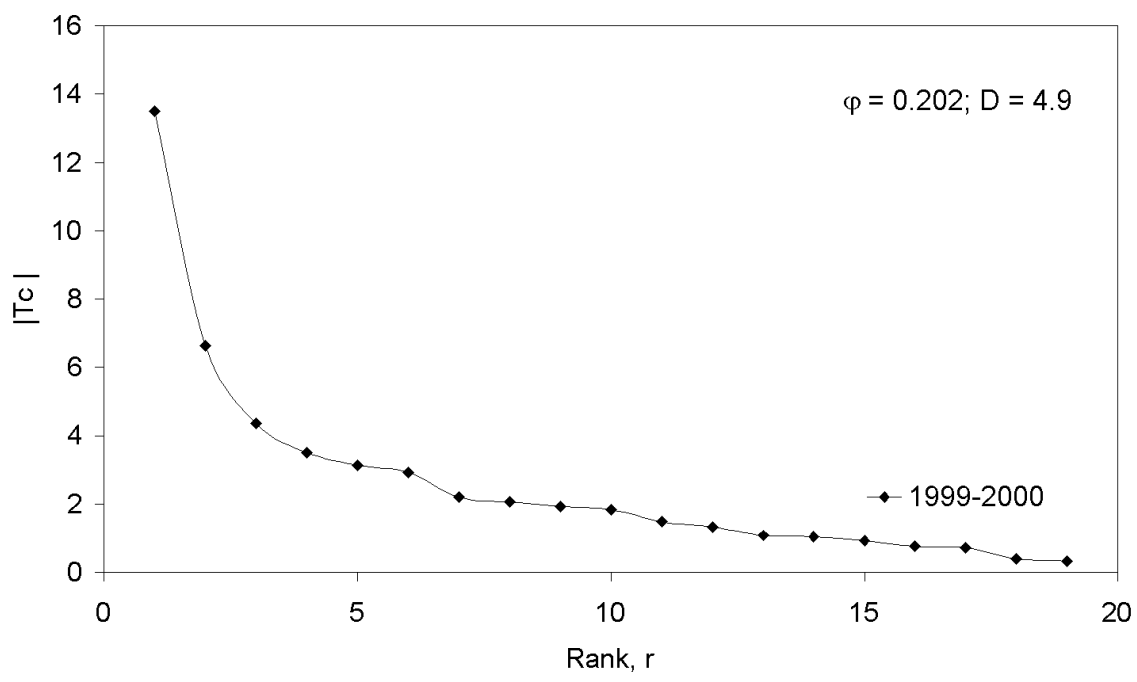

Figure 7. Profile of $T_{\mathrm{c}}$ for the period 1999-2000. The greatest translation capacity belongs to the theme of greatest centrality. It is another case of an elite formation, although not as marked as in the period 1997-1998 
R. BAILÓN-MORENO et al.: The pulsing structure of science

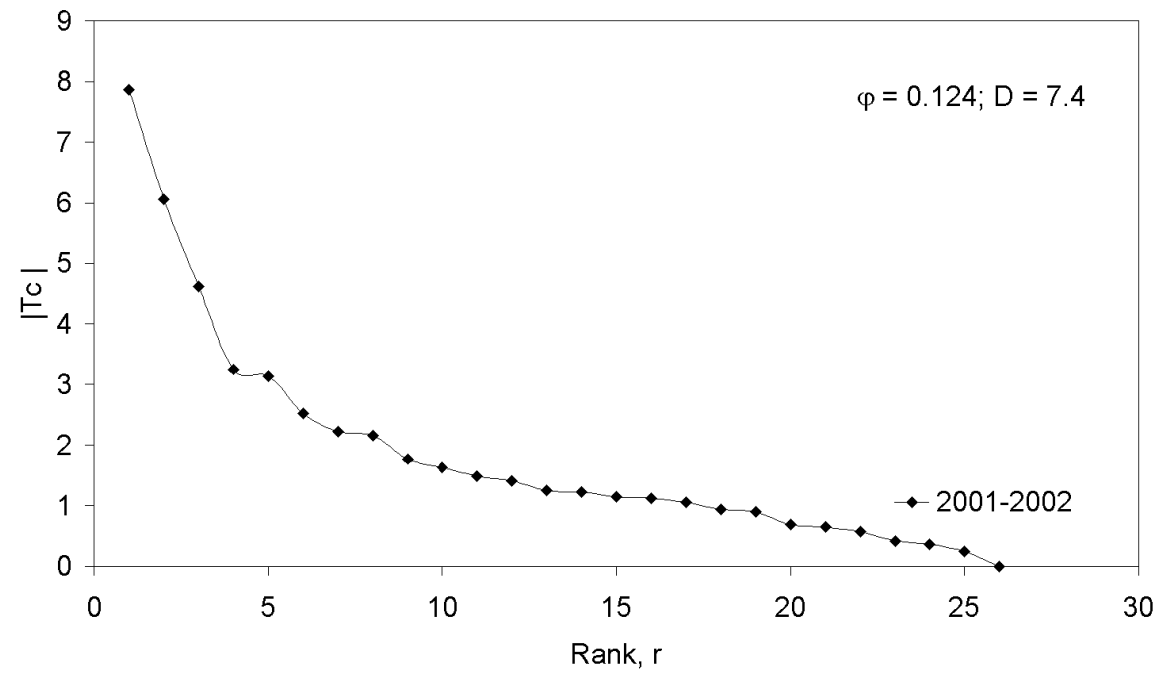

Figure 8. Profile of $T_{\mathrm{c}}$ for the period 2001-2002. The elite is somewhat less marked than in the previous period, as $\varphi$ is also somewhat lower

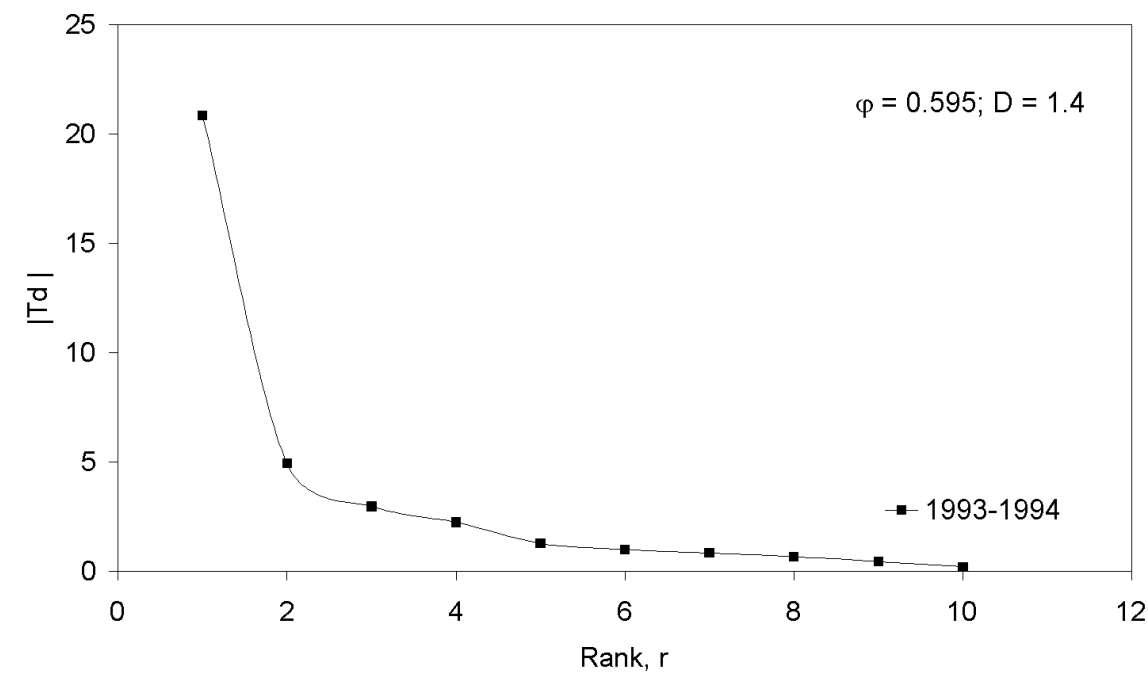

Figure 9. Profile of $T_{\mathrm{d}}$ for the period 1993-1994. The theme of greatest density clearly stands as the elite, since $\varphi$ is sufficiently positive 
R. BAILÓN-MORENO et al.: The pulsing structure of science

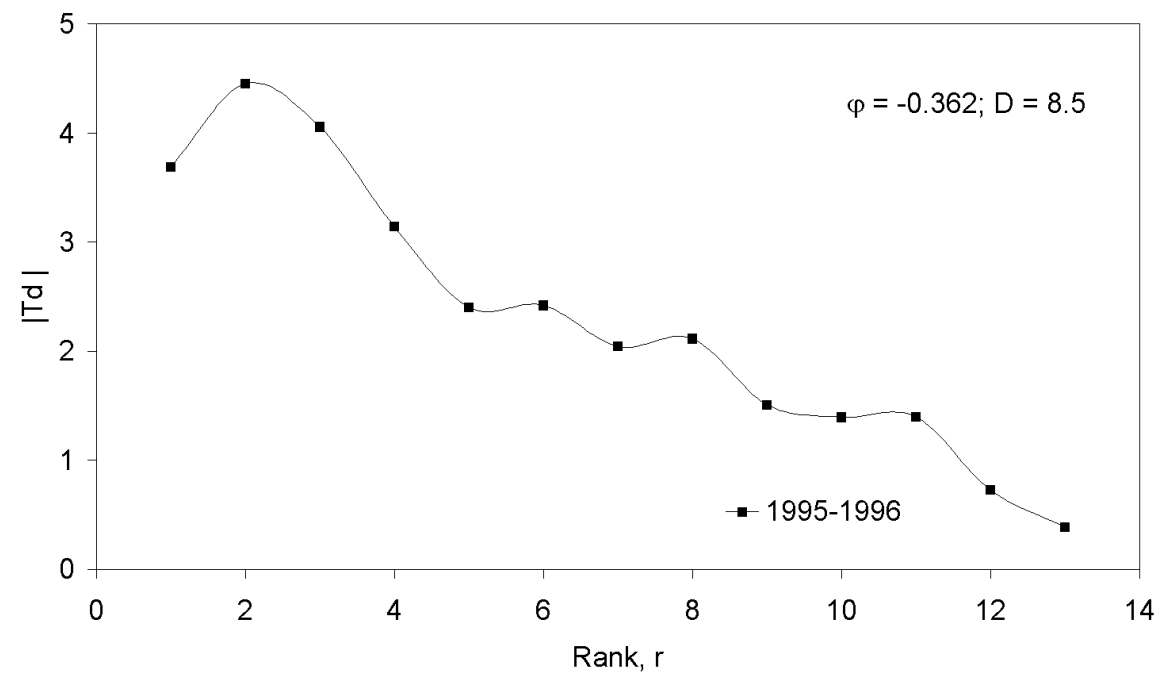

Figure 10. Profile of $T_{\mathrm{d}}$ for the period 1995-1996. As $\varphi$ is slightly negative, the difference in translation between the themes is not very pronounced and the highest value is presented by the second most dense term

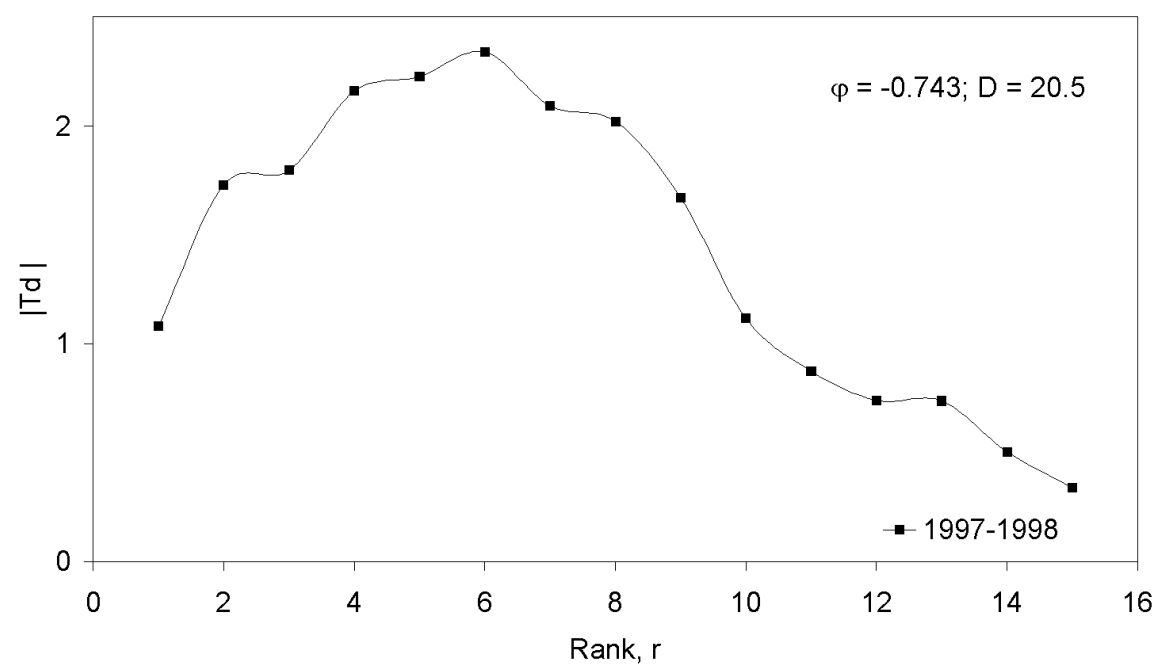

Figure 11. Profile of $T_{\mathrm{d}}$ for the period 1997-1998. This is a clear case of power of the mediocre. The mean density themes present greater translation; $\varphi$ is quite negative 
R. BAILÓN-MORENO et al.: The pulsing structure of science

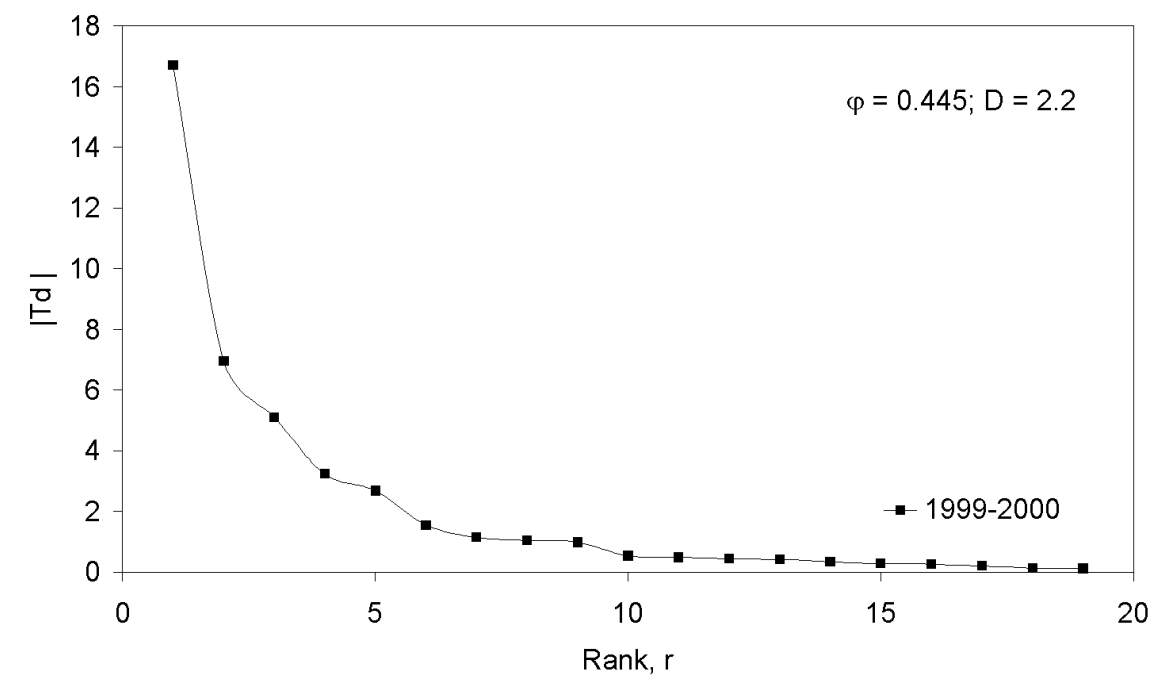

Figure 12. Profile $T_{\mathrm{d}}$ for the period 1999-2000. Here the distribution shows an elite with a translation far greater than that of the middle or low density themes

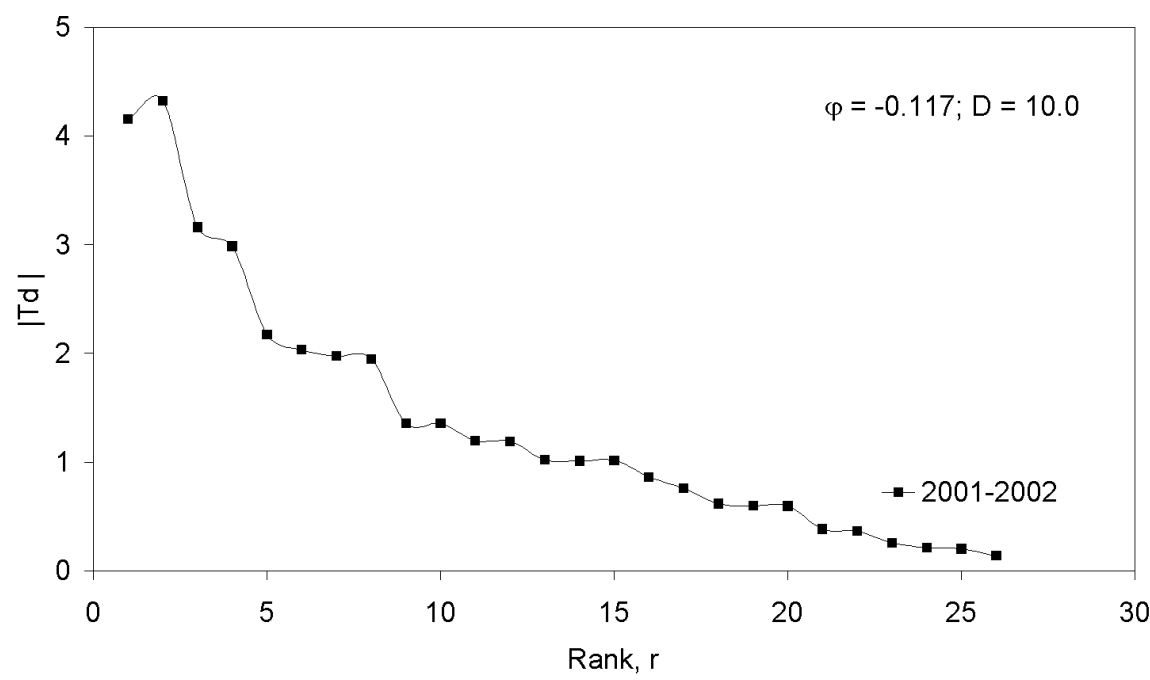

Figure 13. Profile of $T_{\mathrm{d}}$ for the period 2001-2002. As $\varphi$ is slightly negative, the highest value is found in the theme in the second position according to its density. Here, a process of a decline of the elite is beginning 
Both in $T_{c}$ as well as in $T_{d}$, when $\varphi<0$, the greatest translation capacity is not that of the theme that is found with range 1 (the best situated in the strategic diagram) but another theme in a more disadvantageous position. In these cases in which $\varphi$ is negative, we do not use the term fractality but transfractality. It also happens that in the transfractal cases, the number of dimensions becomes very large, implying a greater degree of freedom (it seems reasonable to equate dimensionality with degrees of freedom). When this occurs, the mediocre ones, as postulated in Ortega's hypothesis, have more capacity to act. In these cases, the Matthew Effect is not present nor is the hypothesis of Cole and Cole fulfilled.

It is also established that, when $\varphi>0$, we approach fractal cases. Under these circumstances, the dimensionality drastically diminishes, there is a lower number of degrees of freedom, and the themes with better rank stand far above those of the more disadvantageous rank. Here, Ortega's hypothesis is not fulfilled but the Matthew Effect is.

\section{Science: a pulsing structure between amorphous and crystalline}

Figure 14 presents the value of $\varphi$ for the density and centrality in each period. It can be clearly appreciated that the values of this parameter are not constant with time and their variation cannot be attributed simply to random, but rather there is an oscillating or pulsating pattern. Also, it is confirmed that the behaviour of centrality and of density is similar but has a certain lag of approximately one time period (equivalent to two years). The complete cycle of oscillation in both cases is roughly three periods and thus, according to this, the structure of the scientific field of the physicochemistry of surfactants changes periodically from fractal to transfractal approximately every six years. This implies also that alternatively the circumstances change from favouring the Matthew Effect to later favouring Ortega's Hypothesis. It is to be expected that this is not an isolated case and it does not seem rash to generalize, in agreement with Kuhn, that the construction of science goes through times in which the élite (thematic in this case, since we are analysing the parameters centrality and density of the themes) are preponderant, and after a number of years the intermediate themes (or mediocre ones) acquire greater force. 


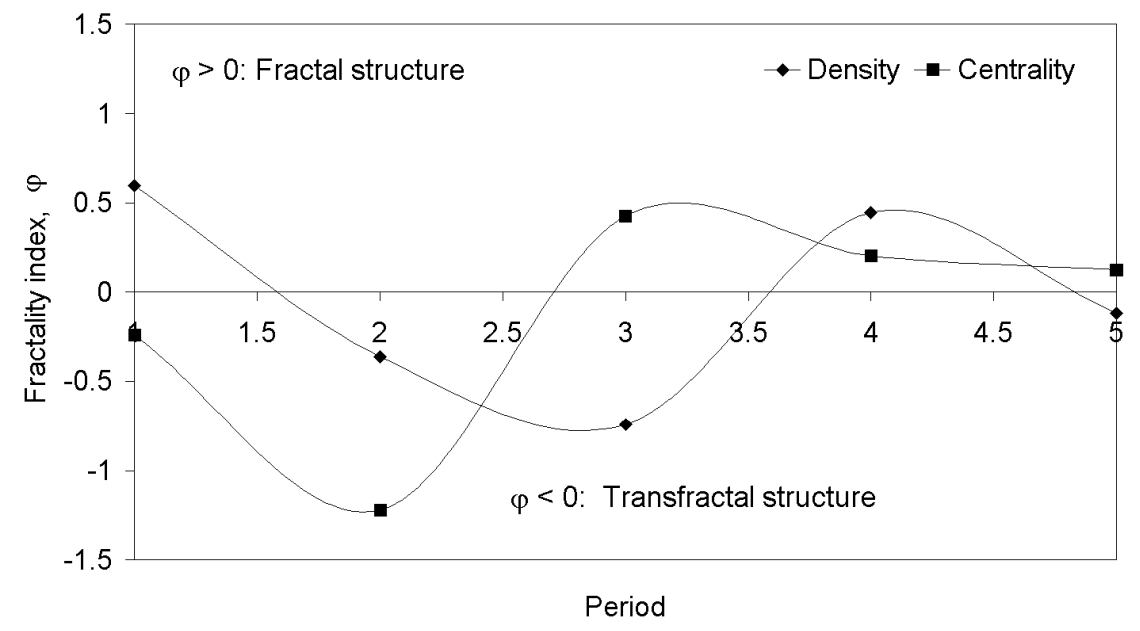

Figure 14. Periodic oscillations of the fractality index, $\varphi$, for centrality and density in the physicochemistry of surfactants

Parallel to the changes in the fractality index, there are changes in dimensionality, or degrees of liberty. Very fractal situations (of few dimensions, self-similar, and therefore crystalline) shift to transfractal situations (of high dimensionality, many degrees of freedom, not self-similar, and which we could call amorphous) (Figure 15).

In addition, if we represent the dimension against the fractality index (Figure 16), we find that there is an exponential relationship:

$$
D=D_{0} e^{-f \varphi}
$$

where $D_{0}$ is the dimension of the translation space at the boundary between fractality and transfractality $(\varphi=0)$, and $f$ is a constant.

Eq. 6 clearly indicates that the degrees of freedom of the scientific network, its more or less crystalline or amorphous character, are necessarily linked to the fractal or transfractal character, respectively, that it presents at any given time.

The pure fractal dimension, or crystalline dimension, $D_{c}$, is reached when $\varphi$ approaches unity:

$$
D_{c}=\lim _{\varphi \rightarrow 1} D=D_{0} e^{-f}
$$




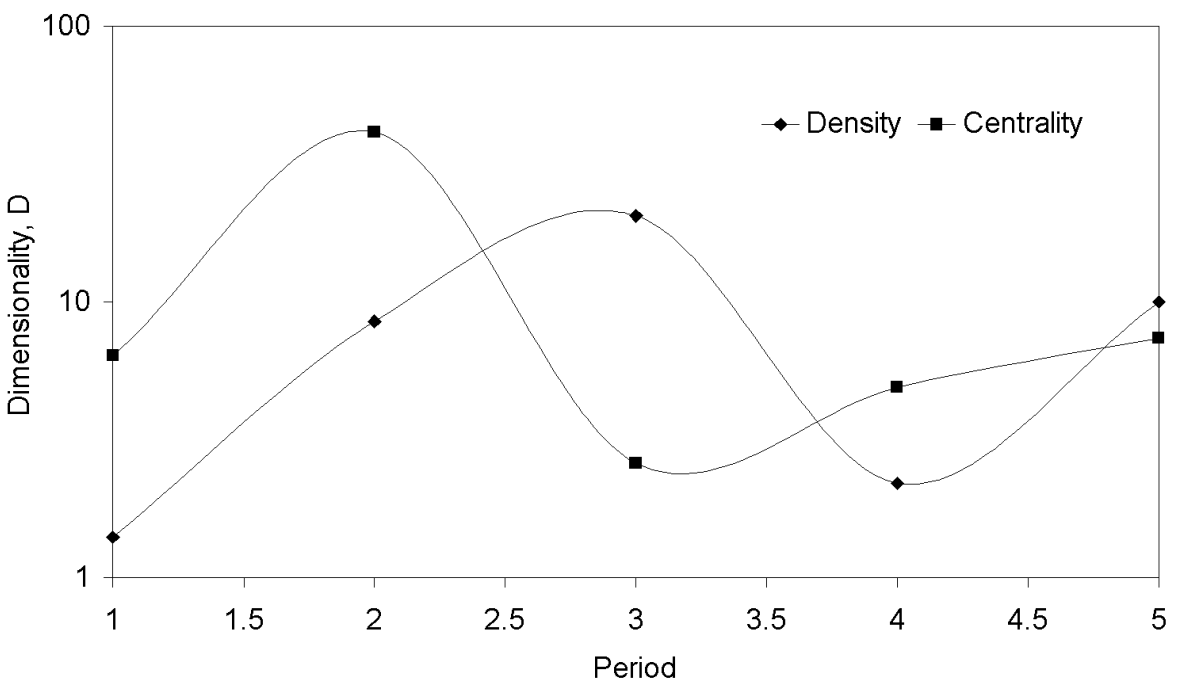

Figure 15. Oscillations in the dimensionality of the network of the physicochemistry of surfactants

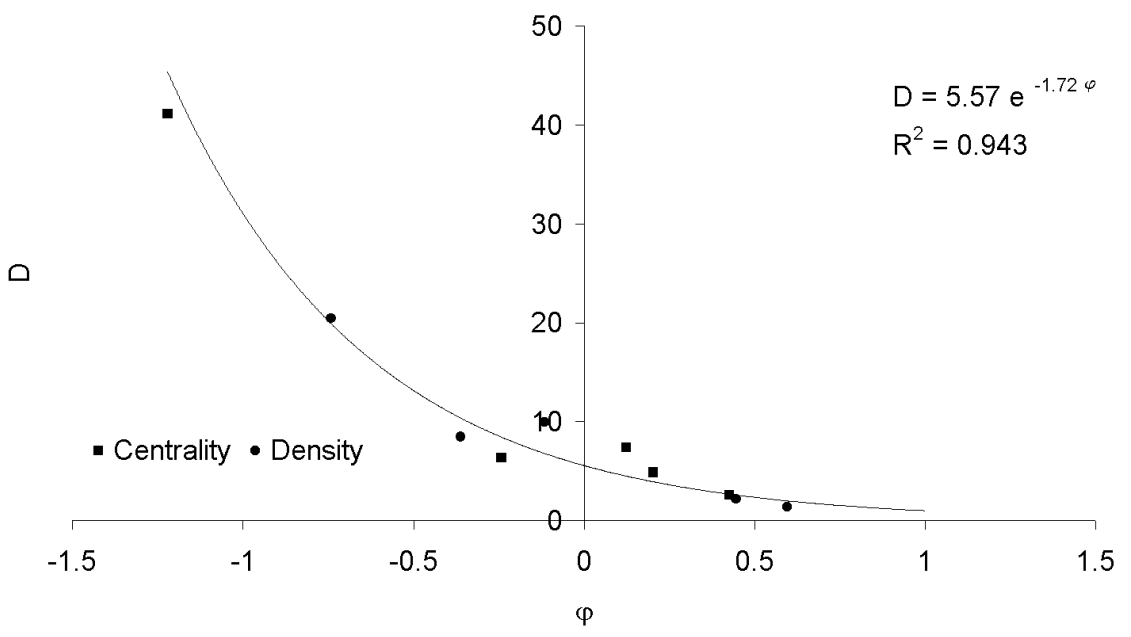

Figure 16. The fractal dimension as a function of the fractality index

In the case of the scientific field of surfactants, with a value of $f=1.72$ and $D_{0}=5.57$, the crystalline dimension of the network is very close to unity (specifically $D_{c}=0.997$ ). It could be stated that at the $100 \%$ fractal extreme, there is only one degree of freedom. 
We define "amorphy", $\alpha$, as the quotient between the dimension of the scientific network at a given instant and the dimension that it would present if it were completely crystalline. It can be easily demonstrated that it is an exponential function of the fractality index:

$$
\alpha=\frac{D}{D_{c}}=e^{f(1-\varphi)} .
$$

From this last equation, it can be deduced that the dimension of the network at a given time is equal to the product of the dimension that it would have if it were completely crystalline by the amorphy that the network undergoes. For an amorphy equal to unity, the Matthew Effect would predominate (associable to the "normal science" of Kuhn), while for higher values the influence of Ortega's Hypothesis appears (associable to "revolutionary science"), which at the extreme where the amorphy is infinite, the situation would be absolute revolution.

In principle, amorphy values lower than unity, or even negative values, are not to be expected, as that would imply hypercrystalline states, which seem not to be supported for now by empirical data. They do not even appear to be reasonable.

As a summary, Figure 17 shows schematically the relationships between the concepts up to now discussed in the present paper.

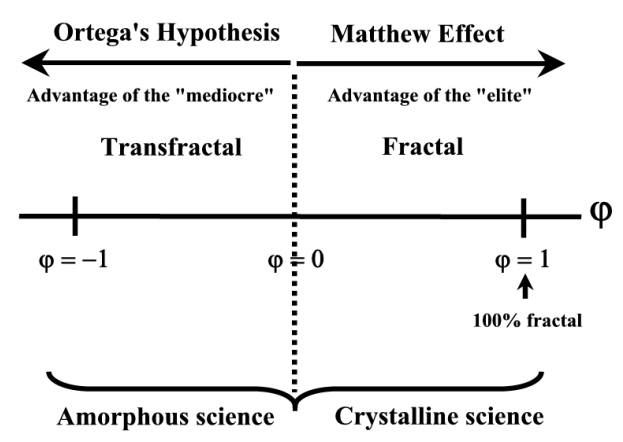

Figure 17. The structure of science, Ortega's Hypothesis and the Matthew Effect

The oscillations or pulsations found appear to imply something extremely important: at certain intervals, opportunities appear in the structure of the scientific network that make it less rigid or crystalline with many degrees of freedom, and a restructuring process begins (amorphous situation) in which the less favoured themes (Ortega's Hypothesis) acquire greater translation capacity. After the reconstruction, the network presents a new relationship of forces, new actors appear, others disappear, and ties between them are change. This situation persists during a rigid phase controlled by the Matthew Effect. 


\section{Conclusions}

This paper shows that finally the two opposing traditional proposals that have been used to explain the behaviour of scientists - the Saint Matthew Effect and Ortega's Hypothesis - may constitute successive phases of the same process of continual renewal in which scientific activity unfolds. This activity undergoes periods of predominance by the Matthew Effect, characterized by the domination of the élite, who defend a certain paradigm which they manifest when, in mathematical terms, $\varphi$ or fractality index tends to 1 . These periods alternate with phases of controversy or struggle of paradigms, during which the scientific structure loses coherence and there are no authors that accumulate all the scientific capital, whereupon the fractality index becomes negative and the term transfractality applies.

From a merely intuitive standpoint, this scheme appears to be quite a reasonable explanation of the succession of periods of stability and change that characterize scientific activity and the general progress of science.

This study was supported by the Spanish Ministry of Science and Technology through projects no. 1FD97-0931 and PB1998-1293.

\section{References}

1. A. J. LotKA, The frequency distribution of scientific productivity. Journal of the Washington Academy of Science, 16 (12) (1926) 317-323.

2. D. J. DE SOlla PRICE, Science since Babylon, Yale University Press, New Haven, CT, 1961

3. R. K. MERTON, Matthew effect in Science. The reward and communication systems of science are considered. Science, 159 (3810) (1968) 56-63.

4. J. R. COLE, S. COLE, The Ortega hypothesis. Science, 178 (1972) 368-375.

5. J. ORTEGA Y GASSET, La rebelión de las masas, Editorial Tecnos (Grupo Anaya, S. A.), Madrid, 2003.

6. E. GARFIELD, Citation analysis as a tool in journal evaluation. Science, 178 (4060) (1972) 471-479.

7. T. S. KunN, The Sttructure of Scientific Revolutions, University of Chicago Press, Chicago, 1962.

8. A. RIP, J. P. COURTIAL, Co-word maps of biotechnology: an example of cognitive scientometrics. Scientometrics, 6 (6) (1984) 381-400.

9. B. LATOUR, Nunca hemos sido modernos: Ensayo de antropología simétrica, Debate, Madrid, 1993.

10. M. CALlon, J. LAw, A. RIP, Mapping the Dynamics of Science and Technology: Sociology of Science in the Real World, The McMillan Press LTD, London, 1986.

11. B. LAtour, Ciencia en acción: Cómo seguir a los científicos e ingenieros a través de la sociedad, Labor, Barcelona, 1992.

12. Callon, M., Representing nature, representing culture. Conference pour l'ouverture du Centre for Social Theory and Technology, 1995.

13. J. P. Courtial, L. Gourdon, A scientometric approach to autism based on translation sociology. Scientometrics, 40 (2) (1997) 333-355.

14. J. P. Courtial, L. Gourdon, Mapping the dynamics of research on autism or the cultural logic of science. Theory and Psychology, 9 (5) (1999) 579-604. 
15. B. LATOUR, Give me a laboratory and I will raise the world. In: K. KNORR-CETINA, M. MUlKAY (Eds), Science Observed: Perspectives on the Social Study of Science. Sage, London, 1983, pp. 141-170.

16. R. RUIZ-BAÑos, Ciencimetría de redes. Análisis de la investigación internacional sobre Arqueología mediante el Método de las Palabras Asociadas (1980-1993). Ph. D. Thesis. Universidad, Granada, 1997.

17. R. Ruiz-Baños, R. Bailón-Moreno, E. Jiménez-Contreras, J. P. Courtial, Structure and dynamics of scientific networks. Part 1: Fundamentals of the quantitative model of translation. Scientometrics, 44 (2) (1999) 217-234.

18. R. Ruiz-BAÑos, R. BAIlón-Moreno, E. JimÉneZ-Contreras, J. P. Courtial, Structure and dynamics of scientific networks. Part 2: The new Zipf's Law, the cocitations's clusters and the model of the presence of key-words. Scientometrics, 44 (2) (1999) 235-265.

19. R. RUIZ-BAÑos, Las traducciones dinámicas de las series temáticas. Propuesta de una nueva clasificación. Actas del IV Congreso ISKO España EOCONSID'99. La Representación y Organización del Conocimiento en sus distintas perspectivas: su influencia en la Recuperación de la Información, Capítulo Español de la Sociedad Internacional para la Organización del Conocimiento (Ed.), Granada, 1999, pp. 193-198.

20. B. LATOUR, S. WOOLGAR, La vida en el laboratorio. La construcción de los hechos científicos, Alianza, Madrid, 1995.

21. B. B. MANDELBRot, An informational theory of the stadistical structure of language. In: W. JACKSON (Ed.), Communication Theory. London, Butterworths Scientific Publications, 1953, pp. 486-502.

22. B. B. MANDElBRot, The Fractal Geometry of Nature, Freeman, New York, 1977.

23. W. SIERPINSKI, Sur une courbe cantorienne qui contient une image biunivoque et continue de toute courbe donné. Comptes Rendus, (162) (1916) 629.

24. B. B. MAndelbrot, Adaptation d'un message à la ligne de transmission. I \& II. Comptes Rendus, 232 (1951) 1638-1640 \& 2003-2005.

25. B. B. Mandelbrot, Structure formelle des textes et communication (deux études). Word, 11 (1954) 424.

26. E. N. LORENZ, Deterministic nonperiodic flow. Journal of the Atmospheric Sciences, 20 (1963) 130-141.

27. G. Julia, Oeuvres de Gaston Julia, Gauthier-Villars, Paris, 1968.

28. A. F. J. VAN RAAN, Fractal geometry of information space as represented by co-citations clustering. Scientometrics, 20 (3) (1990) 439-449.

29. A. F. J. VAN RAAN, Fractal dimension of co-citations. Nature, 347 (1990) 626.

30. R. BAILÓN-MORENO, Ingeniería del conocimiento y vigilancia tecnológica aplicada a la investigación en el campo de los tensioactivos. Desarrollo de un modelo ciencimétrico unificado. $\mathrm{Ph}$. D. Thesis. Universidad de Granada, Granada, 2003.

31. R. BAILÓn-Moreno, E. JuRAdo-Alameda, R. Ruiz-Baños, J. P. Courtial, The unified scientometric model. Fractality and transfractality. Scientometrics, 63 (2) (2005) 231-257.

32. R. Bailón-Moreno, E. Jurado-Alameda, R. Ruiz-Baños, J. P. Courtial, Analysis of the scientific field of physical chemistry of surfactants with the Unified Scientometric Model. Fit of relational and activity indicators. Scientometrics, 63 (2) (2005) 259-276.

33. D. J. DE SOlla PRICE, A general theory of bibliometric and other cumulative advantage processes. Journal of the American Society for Information Science, 27 (5-6) (1976) 292-306.

34. A. BooksteIn, Informetric distributions, Part II: Resilience to ambiguity. Journal of the American Society for information Science, 41 (1990) 376-386. 